\title{
BEING WATCHED BY TV: SURVEILLANCE AT HOME
}

\author{
Ananda Mitra \\ Wake Forest University \\ Winston-Salem, NC 27106, USA
}

\begin{abstract}
The Television (TV) that became a ubiquitous part of households in many parts of the World since World War II has been witnessing a significant transformation since the turn of the Twenty-First Century. Starting in the early 2000s, the TV has morphed in many ways such as in the size and quality of picture it delivers, the kind of content it can offer, and the multiple ways in which it can be used. Yet, in spite of these changes, it has been the case that the TV has remained a site to consume narratives. It is only in the past few years, with the advent of the "smart" TV has the tool been connected to the Internet and can gather information about the viewer in front of the TV instrument. In this essay I argue that the TV, originally the conduit for offering passive narratives to the audience, is transforming into a tool that can watch over the audience and construct a dynamic narrative of the audience, thus operating as tool for surveillance.
\end{abstract}

\section{KEYWORDS}

Surveillance, TV, Narrative, Panopticon

\section{INTRODUCTION}

Since the early days of TV in the developed countries of the West, the technology and the medium had been considered to be a passive device that was the conduit that brought information to the people who would watch the screen seeking anything from entertainment to education. TV has sometimes been called the "idiot tube," for the mesmerizing effect it would have on the watcher who could be distracted to catatonic inactivity just watching TV in a "mindless" way without having to bring any intellectual energy to the process of watching TV. This phenomenon was examined copiously by scholars from many disciplines and numerous theories were proposed and debated that examined the "effects" of watching TV as would be found in many introductory books on mass communication.

\section{THE PASSIVE NARRATIVE}

One important assumption that underpinned the emergent theories claimed that the audience of TV was a relatively passive and often disengaged person (see, e.g., early research by Klapper, 1960). This assumption was especially true for the programs of research that mimicked the natural scientific methods of research devising experiments and interventions with samples selected from the population to understand the effects of $\mathrm{TV}$ in numerical terms, as in the case of development of theories such as cultivation theory often considered to be a central tenet of understanding the effect of TV. Other researchers who subscribed to a more cultural anthropological, critical and cultural interpretations of the role of TV in everyday life sought answers in the ways the audience would talk about television, or through observational studies where the audience would be observed to see how they interacted with the narratives and discourses on television, as in the case of scholar originating in the Birmingham Center for Cultural Studies and offering the vast array of literature on the role of TV within popular culture starting with the work of scholars such as Hoggart (1957). In both approaches, however, there was the shared presumption of relative anonymity of the audience where any individual member of the audience was a part of a larger similar kind of people where the specific individual was unknown to those who created and circulated the content of TV. 
This lack of information about a specific member of the audience was largely a factor of the way in which the TV technology worked from its inception to the time when the Internet became a part of everyday life for large groups of people. Traditional TV technology was designed to deliver a robust image and sound to the audience without the audience having to come to the place where the content was available as in the case of movies. The content distributors had little knowledge of who was watching the content, why they were watching the content or if the audience was liking the content. At the reception end of the process, TV technology was a "passive" tool that merely displayed the content on the screen. This status quo changed with the increasing adoption of the Internet in the public sphere.

With increasing home-based access to the digital network of global computers - the Internet - the interactive computer screen became a conduit to a larger virtual space with increasing libraries of data that the user could access. This data, often residing on computers all over the World, could be accessed by any of the computers using the computer screen. Even though the computer and the TV screen were beginning to look similar, their functions were constantly diverging with the TV screen becoming a site for narratives that the user could not control. The narratives of the TV screen were simply sent out to the user with the expectation that the user would subscribe to the narratives when the screen brought them home, indeed the users were expected to manage the everyday life practices of their lives to suit the demands of the TV screen if the users wanted to access the narratives on the TV screen. On the other hand, the narratives were within the control of the user on the computer screen. Here the user could build an unending narrative by accessing multiple data that were connected by hypertext to each other allowing the user to constantly explore and discover and construct the personalized narrative that the user sought and not what the TV institutions handed out.

The seduction of interactivity, coupled with the primacy of the computer screen over the TV screen led to the demand for a single-screen solution where the screens could be merged into one where the single screen would serve primarily as a conduit for interactions that would allow the user to construct their personalized narrative that would appear on this single converged screen. It is this demand for convergence that allowed the ubiquitous merged screen to become a site for collecting data about individuals.

\section{THE INTERACTIVE NARRATIVE}

The notion of convergence is particularly important in the context of the emergent screen in the private spaces occupied by individual members of the audience. The duality between computer screen as a site with the potential of creating an interactive narrative, such as writing a book, and the TV screen as a site of consuming narrative was increasingly being erased as a single converged screen was replacing the two where the single screen would converge the different functions into one site.

The new digital TV with access to the Internet built into the TV was becoming commonplace by the early 2000s and became nearly ubiquitous within five to six years, especially in the USA where all TV broadcast changed to digital broadcast on June 12, 2009 and nearly $97.5 \%$ of the American homes were ready for the mandatory transition. Within the next several years the transition to digital TV, the nearly ubiquitous availability of broadband connection to the Internet, and the emergence of content conglomerators, producers, and distributors that were distinct from the traditional media content providers offered new narratives to the audience. Thus, the dominance of corporations such as Netflix, Amazon, Hulu, YouTube and others less prominent institutions allowed for narratives to be converged on the now-interactive screen in the private home.

The popularity of the Internet, accompanied with the availability of content producers and distributors mentioned earlier, however, altered the way in which the viewer could interactively construct narratives. First, it became far simpler to shift the viewing time, an advantage that was already available through the more elaborate home-based recording technologies. The viewer now had the ability to seek and find narratives at any time the viewer wanted to consume narratives. Second, the narratives could be obtained from a multitude of sources where the viewer was no longer restricted to the traditional providers of narratives such as the TV channels. The increasing digitization of video (and audio) allowed for narratives to be obtained from sources that would never be considered providers of narratives, including non-institutional sources that could not have afforded to be in the public sphere before the availability of the Internet. In particular, is the example of the Worldwide video-sharing platform - YouTube. A viewer could now call upon narratives that were from individual composers of narratives who would never be found in the traditional media spaces. Third, the viewer could interact with multiple sources of narratives and create a customized "playlist" that specifically would be 
designed to meet the interest of the viewer and could be distinct from other viewers. Even though the viewer was still restricted to the narratives that were connected to the network, the choice was sufficiently large that a viewer could construct a very specific playlist to satisfy the "taste" of the viewer. Finally, all of the narratives, and the queries that create the conglomeration of narratives, could now be done through the interface of the TV screen which transformed from the passive screen to a site of interaction between narratives and the viewer.

The common theme for this transformation is the interactive power attributed to the viewer with the privilege of being able to search for the narratives based on the interests of the viewer. It is precisely this interactivity, now happening through the press of buttons on a TV remote control that transforms the relationship between the viewer and the TV screen which now serves as the gateway for the vast digital space where content is located. It is precisely the nature of the gateway that makes the TV screen the window into the World of the individual viewer who, while watching the narratives, is also being "watched" by the TV screen - in a process of surveillance as TVs were manufactured with listening devices and cameras where the TV could keep an "eye" on its surroundings.

\section{WATCHED BY TV}

The intimate connection between the maintenance of order and discipline becomes the central thesis of the academic examination of the process of surveillance when scholars such as Foucault (1979) begin to connect surveillance to power and discipline. Among the different ideas of surveillance that emerged as important was the notion of the Panopticon which claims that the powerful is constantly watching everything all the time (Bentham, 1995). The panopticon society was built around a strict definition of discipline and in the late 1800 and early 1900s the metaphor was principally used to describe the ways in which totalitarian nations and despots would want to constantly watch everything to maintain power and discipline (see, e.g., Bentham, 1962a, 1962b, 1995; Gandy, 1993; Lyon, 1994, 2003, 2006).

In some cases, however, there is the emergent interest in examining how the watchers could also include corporations and institutions that had a motive unrelated to discipline and power but more interested in understanding the "market" that the institution would be interested in serving (see, e.g., Manokha, 2018). This is especially true for the type of interactive technologies described in this essay. The advent of the technologies described earlier in this essay is, however, concerned with the corporate watching rather than the discipline- and power-based panopticon World that earlier scholars were concerned with. The TV in the house is now constantly watching and monitoring the individuals that use the TV not to stop sedition or to exercise power over the watched but to better understand the "taste" of the watched to ensure that the watcher can best deliver content to the watched that the watched is most likely to consume. In a transactional system where commodities would be sold for profit the process of TV watching the audience is to better commodify the audience who can then be sold to appropriate institutions as a part of a potential market. The process of watching is thus tied to creating the life story of the audience that the TV can obtain by "watching" the data that the individual generates. The panopticon TV in the living room is thus watching a set of different things that early surveillance studies have pointed towards, albeit no longer in the context of discipline and power. There are broadly two kinds of information that the watched offers to the watcher through the modern television - attitudes and behavior.

The information about the attitudes, interests, beliefs and tastes is offered by the specific discourse the watched offers to the different providers of information that bring content to the TV. Consider for instance the simple act of accessing a digital video service such as YouTube that can be accessed on a smartphone and then projected on the TV. In some cases, the TV itself would offer the option of connecting directly to a service such as YouTube. Indeed, it is estimated that nearly $80 \%$ of TVs in American homes would be connected to the Internet by 2019 and any TV that is connected to the Internet can potentially be accessing YouTube without the need for any other ancillary device. One of the key aspects of this connection is the ability of the person being watched search for specific kind of content that can be accessed by the TV and displayed on the screen. The person inscribes attitudes and preferences in the language of the search. There are ways in which such personalization of marketing messages can be turned off through the adjustment of specific settings on an application provided by a corporation. The matter becomes a little different on the TV where the very purpose of the tool, the TV, is to watch narratives, and in the environment of services such as YouTube the viewer must reveal interest information to customize what the person is watching or interested in watching. The process of 
using the TV to access narrative content is intimately connected with the process of revealing to the TV the watcher's interests, attitudes and beliefs.

This information is also connected with the disclosure of behavior patterns. Given that much of the consumption of the content is happening through the content providers such as YouTube, Hulu, Netflix and other Internet-based content delivery system, there is a constant record of what was watched, when it was watched, how it was paid for, and in some cases greater granular information related to the particular watcher in a multi-people home. The attitude and behavior data that such surveillance offers eventually becomes a narrative about the people who are being watched over. It is this narrative that becomes especially important in the new panopticon system produced by the modern TV.

\section{THE STORY TO BE WATCHED}

First, the narrative is cumulative. The TV is constantly watching and updating the narrative. Every time an individual interacts with the TV a new segment is being added to the narrative of the life of the person. The attitude and behavior data being collected by the TV is also constantly updated and the ongoing narrative of the life of a person is stored for future reference. This certainly has its advantages, where a viewer can, for instance, resume watching a show from where it was left off, offering the panopticon TV an opportunity to see how the "rhythm" of a person's life unfolds on a moment to moment basis. Similarly, because the TV knows the story of a person's life, it knows, through its applications, what the person may like to watch next with very well thought out suggestions being offered by the TV with respect to what entertainment the watched individual may be encouraged to watch. The TV watcher's life story is now known to the TV and the TV can gently help to shape that story to reinforce the elements of the story that have been prominent over time. Thus, a person who watched a few episodes of a science fiction, would be encouraged to watch other shows belonging to the same genre.

The longitudinally of the narrative is also connected with the way in which an attempt is constantly made by the different tools of surveillance, including the TV, to triangulate the data to create a narrative about the individual which would encompass all the data about the person. Current laws may make it a little difficult to correlate all the data sets, as in the case of privacy laws in the USA where the medical data of an individual is held sacrosanct and unavailable and generally unconnected with other narrative elements of a person's life. However, there is sufficient data about a person that can be available to the panopticon TV which would allow the TV to surveil the individual in a more precise manner and further help design the ongoing narrative of the person being watched. For instance, gadgets like the Alexa, which respond to voice commands, can be connected to the TV to control the TV with spoken words, as explained in a guide, "Once you link Quick Remote with your Roku device and Alexa, you can use voice commands to tell Quick Remote to navigate the Roku menu system and select any app to start playing." There are two important aspects that need to be noted in these instructions, first, it shows how to connect three different applications (Quick Remote, Roku and Alexa) to each other to have the convenience of sending voice commands to the panopticon TV. All these three systems are sharing the data with each other and thus creating a robust narrative about the person who is being watched.

The second important aspect pointed out in these, and numerous other such instructions, is that the user, or the watched, is offering the data to construct the narrative. There are no hidden cameras or stealthy sensors that are surreptitiously watching the person. On the other hand, the person chose to find the convenience of talking to the TV and thus voluntarily obtained the devices and the applications which help to create the dynamic narrative, that eventually makes the life of the person more comfortable. Indeed, this comfort is best maintained if the person's life story is fully known to the panopticon TV and its army of other devices that is constantly updating the narrative of the person and creating the zone of comfort for the person that eventually becomes comfort for the analog self where the digital narrative helps to predict what the analog self needs. Consider, for instance, the notion of Internet of Things (IoT) that hopes to convert information from and about every device that surrounds an individual to a centralized interconnected database about the person making the life story as complete as possible. When such projects come to fruition the surveillance, aided by the voluntary data offered by the individual, would transcend the TV. In that future, all devices, including the TV, would be geared to collating the most complete life story of the watched. 


\section{CONCLUSION}

There are a few things worthy of note with respect to the way in which the TV has transformed into a tool for watching the watcher. First, this process has not been forced upon a population who had no option but to be watched. A small amount of knowledge about the ways in which the tools are watching us, can allow us to shut off the surveillance. None of these tools, including the TV, makes the data collection process a "required" activity to use the tool in its basic and rudimentary way. One can certainly watch television shows broadcast "over the air" without connecting the TV to the Internet. In a similar way, it is possible to use the Alexa speaker as only a portable speaker connected to a smartphone that has music stored in it.

However, as these examples show, when a user chooses to not connect the TV to the Internet, or Alexa to its manufacturer, and the smartphone to a data plan, the user is sacrificing the ability to use the tools to their full potential. Additionally, the user is sacrificing access to the numerous programming options offered through these tools. There is, therefore, a constant tension between the inclination to maintain a sense of privacy while watching TV and retaining the convenience of the TV making suggestions about what would be interesting to watch. If the TV is allowed to surveil, and it is connected with the other tools that surround the TV then it will eventually be able to create an increasingly complete life story of the person who uses the TV. This complete life story could become the way in which the TV constructs a mediated reality for the person who is being watched. As discussed earlier, this reality can become progressively myopic and an echo chamber within which the person would reside while the panopticon TV creates the comfortable media space for the person.

This future is increasingly realistic since the function of TV as the bearer of the programs offered "over the air" or even through the cable system that became common place in the 1980s is quickly shifting. In many parts of the World, there is the increasing tendency to "cut the cord" and get rid of the cable delivery of programming. Cable companies are increasingly facing a threat where the centrality of program delivery by cable is being replaced by program delivery via the Internet. Numerous companies such as Amazon, Roku, and Apple are offering accessories that could be connected to the TV and program would be delivered through the connection of the accessory to the Internet. Thus, a Roku "stick" can connect to the Internet and the programs would be offered by Roku in collaboration with other content aggregators such as Sling, YouTube, Hulu to name a few. In some cases, a complete ecosystem is produced by a company like Amazon that would offer the accessory for the TV, a household voice activated information retrieval system such as Alexa, and content through the vast store of content that Amazon owns. As the user is migrating to these options, the user is also required to share information through the conduit of the TV with all these different corporations that continue to watch the watcher. It is indeed a World of constant surveillance, whenever the TV is switched on.

\section{REFERENCES}

Bentham, J. (1995). The Panoptic Writings. London: Verzo.

Bentham, J. (1962a). Principles of Penal Law. In (John Bowring, Ed.), The Works of Jeremy Bentham: Volume I, 365-580. New York: Russell and Russell.

Bentham, J. (1962b). The Rationale of Evidence. In (John Bowring, Ed.), The Works of Jeremy Bentham: Volume I, 201-585. New York: Russell and Russell.

Fisher, W. R. (1984). Narration as Human Communication Paradigm: The Case of Public Moral Argument, Communication Monographs, 51, 1-22.

Foucault, M. (1979). Discipline and Punish: The Birth of the Prison. New York: Advantage Books.

Klapper, J.T. (1960). The effects of mass communications. Oxford, England: Free Press of Glencoe.

Kozloff, S. (1992). Narrative Theory and Television. In (R. Allen, Ed.) Channels of Discourse Reassembled. Chapel Hill: $\mathrm{U}$ of North Carolina Press.

Lyon, D. (1994). The Electronic Eye: The Rise of Surveillance Society. Minneapolis, MN: University of Minnesota Press.

Lyon, D. (2003). Surveillance as Social Sorting. New York: Routledge.

Lyon, D. (2006). Theorizing Surveillance: The Panopticon and Beyond. Devon: Willan.

Manokha, I. (2018). Surveillance, Panopticism, and Self-Discipline in the Digital Age. Surveillance \& Society 16(2): 219-237.

Sherwell, P. and Barnett, L. (2013). Barack Obama 'approved tapping Angela Merkel's phone 3 years ago.' The Telegraph. Thorburn, D. (1976). Television Melodrama. In (R. Adler, Ed.) Television as a Cultural Force, 77-94. New York: Praeger. 